\title{
TRANSPLANTE HEPÁTICO NO TRATAMENTO DE LEUCINOSE: RELATO DE EXPERIÊNCIA
}

\author{
Liver transplant to treat leucinosis: report of an experience
}

Fernanda de Oliveira Procópio, João Seda, Eduardo Antunes, Vera Lúcia Andrade de Aquino

\section{RESUMO}

Introdução: A leucinose ou doença da urina de xarope de bordo (DXB) de caráter genético causa deficiência do complexo enzimático e acúmulo de aminoácidos leucina, valina e isoleucina, resultando em déficits neurológicos. $O$ tratamento indicado é o transplante (TX) hepático intervivos dominó, onde o fígado é disponibilizado para a lista de espera da Central de Transplantes. Objetivo: Relatar a experiência do Hospital Sírio-Libanês (HSL) na realização de TX hepático em crianças portadoras de DXB. Método: Estudo de relato de experiência qualitativo, descritivo e observacional. Resultado: Desde 2007, foram transplantadas 213 crianças; destas, sete eram portadoras de DXB e três transplantaram. Após avaliação multiprofissional, foram inscritas no Cadastro Técnico Único da Central de TX de São Paulo e submetidas a TX hepático intervivos. Procedentes do Estado do Amazonas e do Rio de Janeiro, as idades, no momento do TX, eram: um ano e sete meses, um ano e onze meses e dois anos e dez meses. Todas possuíam déficit inicial de sucção, a partir dos cinco dias de vida; duas crianças com PELD inicial corrigido de 1 para 3 e uma criança de 4 para 12, impossibilitando ativação em lista. Os doadores vivos eram aparentados, sendo, a mãe para dois e o pai para um. O tempo médio de internação na UTI foi de quatro dias e, na unidade de internação, de 10 dias. Não houve recidiva da DXB nas crianças transplantadas, bem como nas receptoras do fígado portador da doença. Conclusão: As crianças portadoras de DXB puderam ser beneficiadas com o TX de fígado intervivos e doaram seus órgãos para outras crianças em lista de espera. Observamos que o TX dominó proporciona a não manifestação da DXB em todos os receptores e há melhora progressiva dos déficits neurológicos.

Descritores: Transplante de Fígado; Doença da Urina de Xarope de Bordo; Erros Inatos do Metabolismo.

\section{Instituição:}

Serviço de Captação e Transplante de Órgãos e Tecidos Hospital Sírio-Libanês, São Paulo/SP, Brasil

\section{Correspondência:}

Fernanda de Oliveira Procópio

Rua Rui Barbosa, 361 / 133, BI 1, CEP 09190-370 - Santo André/SP Tel: (11) 99566-2756

E-mail: fernanda.oprocopio@hsl.org.br.

Recebido em: 27/11/2015

Aceito em: 18/12/2015

\section{INTRODUÇÃO}

O Transplante Hepático é um procedimento terapêutico, adotado para pacientes portadores de doença hepática crônica ou aguda, nos quais os tratamentos conservadores não se mostraram efetivos. ${ }^{1}$

No ano de 2014, foram realizados 1.755 transplantes hepáticos no Brasil, dos quais 190 foram em pacientes pediátricos; destes, $110 \mathrm{com}$ doador vivo e $80 \mathrm{com}$ doador falecido; porém, a necessidade estimada para o ano foi de 4.769. De janeiro a junho de 2015, foram realizados 835 transplantes, sendo que a lista de espera ativa em junho apresentava 1.448 pacientes listados..$^{2,3}$ 
O sucesso do transplante de fígado depende de avaliação pré-operatória adequada do paciente. Isso se justifica devido ao reconhecimento de que o sucesso da cirurgia depende, em princípio, do diagnóstico da doença de base, da determinação de sua extensão e do grau de repercussão sistêmica..$^{1,4}$

A leucinose ou doença da urina de xarope de bordo (DXB), também conhecida em inglês por Maple Syrup Urine Disease (MSUD), é uma patologia rara, de caráter genético autossômico recessivo. Os primeiros casos foram descritos em 1954, por Menkes, Hurst e Craig. Verifica-se que a mutação dos genes (BCKDHA, BCKDHB, DBT e DLD) provocam um déficit na atividade do complexo desidrogenase de ácido de cadeia ramificada alfa-ceto (BCKDC). A deficiência desse complexo enzimático causa acúmulo elevado de aminoácidos de cadeia ramificada (BCAA) leucina, valina e isoleucina e de seus alfa-cetoácidos. Estes não sendo metabolizados, têm seus níveis plasmáticos e urinários elevados, causando alteração neurológica e odor característico na urina. ${ }^{5-7}$

Devido à grande variedade dos genes responsáveis pela codificação da DXB estar localizada em diferentes cromossomos, a doença também se manifesta sob diferentes formas, denominadas: forma clássica, forma intermitente, forma tiamina-responsável e forma dihidrolipoli desidrogenase (E3)-deficiente, afetando uma em cada 185.000 crianças recém-nascidas em todo o mundo. A incidência dessa doença em locais como Mennonite e Pensnsilvania nos Estados Unidos chega a um caso em 200. No Brasil, não existe mensuração. ${ }^{5,7}$

As várias formas de apresentação da doença condicionam estados de gravidade distintos. Inicialmente, os recémnascidos parecem normais, sendo que os sintomas aparecem cedo ou mais tardiamente, de acordo com a forma da doença. A forma clássica, que representa a mais severa e comum da doença (cerca de $80 \%$ dos casos), apresenta $50 \%$ de aminoácidos derivados da leucina. Cerca de um quinto dos doentes com MSUD clássica acabam por morrer no decurso de complicações agudas precipitadas por infecção. 5,8

O diagnóstico precoce da doença é fundamental na prevenção do quadro severo de alterações neurológicas que se instalam. Pode ser laboratorial no recém-nascido e efetua-se através da elevação dos aminoácidos no sangue, plasma e urina. Pode ser feito ainda no prénatal através da amniocentese. ${ }^{5}$

O tratamento deve ser iniciado imediatamente após o diagnóstico e consiste em reduzir os níveis de leucina através da infusão de alta dose de glicose para estimular a secreção de insulina e suprimir o catabolismo protéico. Se isso falhar, intervenções invasivas como a diálise peritoneal ou hemodiálise, podem ser necessárias. Durante a fase de manutenção, o tratamento consiste na inibição do catabolismo protéico, manutenção da síntese de proteínas e prevenção da deficiência de aminoácidos essenciais, possível por meio de ingestão de proteína na forma de hidrolisado de aminoácidos sem leucina, isoleucina e valina. A mais utilizada é a BCAA, um produto de alto custo, e não fornecido pelo Sistema Único de Saúde (SUS). Além disso, os exames laboratoriais necessários para o diagnóstico dessa condição também não são fornecidos pelo SUS e só estão disponíveis em alguns centros universitários ou laboratórios médicos privados. Em casos mais graves, tem sido utilizado o transplante de fígado, substituindo o órgão com o gene alterado por um órgão normal. Desta forma, os aminoácidos de cadeia ramificada podem ser metabolizados normalmente..$^{7,9,10}$

O prognóstico dos pacientes com leucinose está melhorando, devido ao seu rápido diagnóstico, antes do estabelecimento de lesões irreversíveis, pela experiência cumulativa sobre a doença e a evolução dos recursos terapêuticos, como a elaboração de fórmulas enterais e parenterais especiais. ${ }^{9}$

De acordo com a Portaria $\mathrm{n}^{\circ} 2.600$, de 21 de outubro de 2009, do Ministério da Saúde, o transplante hepático é indicado para os que estão em tratamento de doenças metabólicas severas e irreversíveis. Esse procedimento corrige os níveis de BCAA, elimina a crise metabólica e melhora os resultados em longo prazo de pacientes com DXB. ${ }^{11}$

O fígado é responsável por $15 \%$ da produção enzimática e, com o transplante hepático, a atividade enzimática é restaurada em pacientes com DXB. Observa-se diminuição na concentração de leucina, horas após a realização do transplante em pacientes com DXB. ${ }^{12}$

Com os avanços nas técnicas cirúrgicas e de imunossupressão, o transplante hepático tem registrado nos últimos 25 anos, aumento da sobrevida e melhoria da qualidade de vida do transplantado. Apesar desse progresso impressionante, restrições no abastecimento de doadores continuam a representar um problema para o avanço no campo de transplante, limitando drasticamente o número de pacientes que poderiam beneficiar-se dessa técnica. ${ }^{13}$

Um dos pontos evidenciados com a realização do transplante nos portadores de Leucinose é a possibilidade de disponibilização do fígado para a lista de espera através do transplante dominó. ${ }^{7}$

Muitas enzimas metabólicas, que são deficientes nessas condições hereditárias, são na verdade, produzidas no fígado e, portanto, o transplante de um fígado contendo a atividade enzimática em falta pode curar essas 
doenças. Embora alguns dos distúrbios metabólicos corrigíveis por transplante de fígado possam causar grave doença do parênquima hepático, outros o deixam com função hepática relativamente bem-preservada. $O$ paciente com essa doença metabólica necessita de um fígado transplantado, mas seu próprio fígado pode ser utilizado como enxerto de dominó. ${ }^{13}$

O trabalho em questão visa demonstrar a realidade das crianças portadoras de Leucinose, que pela estabilidade clínica apresentam PELDs baixos, impossibilitando permanência ativa em lista e, por consequência, a realização do transplante com doador falecido, além da possibilidade de diminuição da fila de espera para o transplante hepático com a realização do transplante dominó.

\section{MÉTODO}

O trabalho visa relatar a experiência das autoras com pacientes portadores de Leucinose, sendo uma pesquisa qualitativa descritiva observacional.

O Comitê de Ética em Pesquisa do Hospital SírioLibanês foi notificado quanto ao trabalho, definida a resolução CNS/MS 196/96 e suas complementares, a pesquisa não necessitou de submissão para apreciação ética, por tratar-se de relato de experiência da própria coautora.

Primeiramente, para sua realização, utilizou-se estrutura hospitalar, que forneceu vários recursos, tais como, um Ambulatório para o atendimento desses pacientes, Pronto Atendimento para atender intercorrências, Serviço de Diagnóstico para realização de exames, Unidade de Terapia Intensiva Pediátrica, grupo multidisciplinar para avaliação e acompanhamento pré e pós-TX.

Vale ressaltar que o fígado da criança portadora de Leucinose foi disponibilizado para a lista de espera, porém, como a realização do transplante dominó não é realidade comum em nosso país, foi disponibilizado para o nosso serviço.

O estudo foi realizado no Hospital Sírio-Libanês, observando os transplantes realizados desde 2007 até o momento.

\section{RESULTADO E DISCUSSÃO}

Desde 2007 foram avaliadas 213 crianças neste serviço; destas, sete tiveram diagnóstico de DXB; do total dessas crianças portadoras, três realizaram o transplante até o momento.
As crianças foram encaminhadas ao nosso serviço já com o diagnóstico de Leucinose. O pediatra, na avaliação inicial, analisou a necessidade de transplante hepático como terapêutica para a hepatopatia. Após preencher os critérios clínicos para o transplante, as crianças foram avaliadas pela equipe cirúrgica, de enfermagem, serviço social e nutricionista. Os casos foram discutidos em reunião científica, individualmente, considerando-se a idade da criança, o grau de disfunção da doença hepática, bem como a ausência de tratamento conservador com melhor resultado na probabilidade de sobrevida comparado ao transplante, identificando e tratando as complicações da hepatopatia, para que a criança estivesse apta ao transplante, descartando contra indicações ao procedimento.

Para a documentação, foi realizado aminoacidograma da criança e do doador, dos pais e do receptor, análise de DNA e de recordatório alimentar do receptor, na semana que antecedeu o exame; as amostras foram enviadas para avaliação ao Serviço de Genética Médica no Hospital de Clínicas de Porto Alegre, referência nacional de assistência e pesquisa sobre DXB, conforme protocolo estabelecido por essa instituição. Outros sinais e sintomas foram avaliados como: padrão do choro, ocorrência de alterações respiratórias, problemas na sucção, aceitação alimentar, tônus muscular, odor anormal, frequência de convulsões, perda de peso, alterações metabólicas, lesões em pele, alterações na marcha e comportamento, dentre outros.

Após avaliação multiprofissional, foram inscritos no Cadastro Técnico Único da Central de TX de São Paulo e submetidos ao TX hepático intervivos. Em uma criança procedente do Estado do Amazonas e duas do Rio de Janeiro, as idades no momento do TX eram: um ano e sete meses, um ano e 11 meses e dois anos e 10 meses; duas crianças com PELD inicial corrigido de 1 para 3 e a outra, de 4 para 12, impossibilitando ativação em lista. Os doadores vivos foram aparentados, sendo a mãe para dois e o pai para um.

As crianças em questão apresentaram avaliações neurológicas dos serviços de origem, confirmando atraso no desenvolvimento neuropsicomotor e na aquisição e desenvolvimento da linguagem.

Todas possuíam déficit inicial de sucção, a partir do quinto dia de vida. O tempo médio de internação na UTI foi de quatro dias e, na unidade de internação, de 10 dias, sem complicações cirúrgicas.

Com a realização do transplante, foi possível observar melhora no desenvolvimento e perceptível melhora da interação de forma contextualizada, não mais necessitando de gastrostomia para alimentação, sendo 
esta, hoje, realizada por via oral; desenvolvimento motor, como sentar, e brincadeiras com movimentos de chute, dentre outros.

As crianças seguem no pós-Tx com acompanhamento neurológico, nutricional, fonoaudiólogo e fisioterápico, com realizações de coleta de aminoacidograma e recordatório alimentar, conforme cronograma estipulado pela instituição de referência.

Os receptores de fígado portadores de DXB mantiveram níveis quase normais de aminoácidos no plasma, demonstrando que não desenvolveram a doença. Esse fenômeno pode ser explicado pelo fato de o receptor dominó ter mantido sua normalidade na oxidação de leucina extra-hepática. ${ }^{11}$

Nas crianças transplantadas não houve recidiva da $\mathrm{DXB}$, bem como nas receptoras do fígado portador da doença.
A pesquisa evidenciou a necessidade de inclusão desse exame juntamente com o Teste de Guthrie ou mais conhecido como "Teste do Pezinho", para diagnóstico precoce, evitando a progressão de déficits neurológicos e mortalidade; com introdução de dieta específica precocemente e avaliação para possível transplante, avaliação de neurologista no pré e pós-Tx, bem como de nutricionista, fisioterapeuta e fonoaudióloga.

\section{CONCLUSÃO}

As crianças portadoras de DXB puderam ser beneficiadas com o TX de fígado intervivos e doaram seus órgãos para outras crianças em lista de espera.

Observamos que o TX dominó proporciona a não manifestação da DXB em todos os receptores e melhora progressiva dos déficits neurológicos.

\section{ABSTRACT}

Introduction: Leucinosis, or maple syrup urine disease (MSUD) has a genetic feature causing deficiency in the enzyme complex and high leucine, valine and isoleucine amino acids levels, resulting in neurological deficit. Domino liver transplant (TX) in living donors is the recommended treatment, in which the liver is made available to the Central Transplant waiting list. Purpose: To report the experience at Hospital Sírio-Libanês (HSL) in performing liver transplant in children suffering from MSUD. Methods: Study report of qualitative, descriptive and observational experience. Results: Since 2007, 213 children have been transplanted; mong them, 7 presenting MSUD 3 were transplanted. After a multidisciplinary assessment, they were enrolled in the Single Technical Record of the São Paulo Central Transplant and submitted to living donor liver transplant. Coming from the states of Amazonas and Rio de Janeiro, their ages at the time of the transplant were: 1 year and 7 months, 1 year and 11 months and 2 years and 10 months. All of them had initial suction deficit from the 5th day of life on; two children with initial PELD corrected from 1 to 3 , and one child from 4 to 12, precluding activation on the list. The living donors were their relatives, two of them being the mother, and one, the father. The average hospital stay was 4 days in the $\mathrm{UCl}$, and 10 days in the inpatient unit. Children who were transplanted did not have MSUD recurrence, none of the liver receptors presented relapse of the disease. Conclusion: Children suffering from MSUD were benefited by the living-donor liver transplant, and they donated their livers to other children on the waiting list. We observed that domino transplant (TX) provides no MSUD manifestation in the receptors, and the neurological deficits have a progressive improvement.

Keywords: Liver Transplantation; Maple Syrup Urine Disease; Metabolism Inborn, Errors. 


\section{REFERÊNCIAS}

1. Castro-Silva Jr O, Sankarankutty AK, Oliveira GR,ET AL. Transplante de fígado: indicação e sobrevida. Acta Cirurgica Brasileira. 2002;17(3):83-91.

2. Registro Brasileiro de Transplante. Dimensionamento dos transplantes no Brasil e em cada estado. RBT 2014 (JAN/DEZ) - ABTO. Disponível em: http://www.abto.org.br/ abtov03/Upload/file/RBT/2014/rbt2014-lib.pdf. Acesso em 29 de setembro de 2015.

3. Registro Brasileiro de Transplante. Dimensionamento dos transplantes no Brasil e em cada estado. RBT 2015 (JAN/ JUNHO) - ABTO. Disponível em: http://www.abto.org.br/ abtov03/Upload/file/RBT/2015/rbt2015-1sem-lib2907.pdf. Acesso em 29 de setembro de 2015.

4. Castro-Silva Jr O, Sankarankutty AK, Oliveira GR,ET AL. Transplante de fígado: indicação e sobrevida. Acta Cirurgica Brasileira. 2002,17(3):83-91.

5. Andrade FP, Carvalho MP, Martinelli T, ET AL. Doença do xarope de boldo: semiologia e terapêutica. Grupo editorial: Moreira Júnior. Pediatria Moderna Out 12 V 48 N 10.

6. Menkes JH, Hurst PL, Craig JM. A new syndrome: progressive amilial infantile cerebral dysfunction associated with an unusual urinary substance. Pediatrics 1954;14:462-6.

7. Heber S, Schwartz IVD, Nalin T, et AL. Maple Syrup Urine Disease in Brazil: a panorama of thelast two decades. J Pediatr (Rio J). 2015.
8. Sociedade Portuguesa de Pediatria consensos e recomendações. Consenso para o tratamento nutricional da leucinose. Sociedade Portuguesa de Doenças Metabólicas. Acta Pediatr Port 2007;38(3):120-8.

9. Valadares ER, Oliveira JS, Talamo LEP. Tratamento metabólico da doença da urina do xarope de boldo. Rev Med Minas Gerais 2010;20(2):255-8.

10. Funchal C, Wajner RP, Wajner M. Parametros Bioquímicos de alterações do citoesqueleto no modelo experimental da doença do xarope do bordo. Tese apresentada ao curso de Pós-Graduação em ciência Biologicas-Bioquimica da Universidade Federal do Rio Grande do Sul. Porto Alegre, 2005.

11. Popescu I, Dima SO. Domino Liver Transplantation: How Far Can We Push the Paradigm? LIVER TRANSPLANTATION 2012;18:22-8

12. Feier FH, Miura IK, Fonseca EA, et AL. Successful domino liver transplantation in maple syrup urine disease using a related living donor. Brazilian Journal of Medical and Biological Research. 2014;47(6):522-6.

13. Kitchens WH. Domino liver transplantation: indications, techniques, and outcomes. Transplantation Reviews 2011;25:167-77. 